\title{
Review and Update of the Risk Factors and Prevention of Antiresorptive-Related Osteonecrosis of the Jaw
}

\author{
Ha Young Kim
}

Division of Endocrinology and Metabolism, Department of Internal Medicine, Gangneung Asan Hospital, University of Ulsan College of Medicine, Gangneung, Korea

Antiresorptive-related osteonecrosis of the jaw (ARONJ) is a rare but serious adverse event of bisphosphonate or denosumab administration; it is associated with severe pain and a deteriorated quality of life. Since its first report in 2003, there have been many studies on its definition, epidemiology, pathophysiology, diagnosis, and treatment. Nevertheless, the epidemiology and mechanisms underlying this condition have not yet been fully delineated and several risk factors are known. Moreover, as there is no effective treatment currently available for osteonecrosis of the jaw, prevention is essential. Furthermore, close cooperation between prescribing physicians and dentists is important. The aim of this review was to provide up-to-date information regarding the risk factors and prevention of ARONJ from a physician's perspective.

Keywords: Diphosphonates; Denosumab; Osteonecrosis; Risk factors

\section{INTRODUCTION}

Bisphosphonates (BPs) are the most widely used class of drugs for osteoporosis treatments in Korea. Long-term use-related rare side effects such as osteonecrosis of the jaw (ONJ) and atypical femur fracture have been reported for these drugs; hence, it is recommended that decision to discontinue BPs after 3 to 5 years of BP treatment should be considered for women not at high fracture risk [1]. Bisphosphonate-related osteonecrosis of the jaw (BRONJ) was first described by Marx [2] in 2003. Since then, the scope has been expanded through many cases and related studies.

In addition to BPs, the anti-receptor activator of nuclear factorkB (RANK) ligand (RANKL) antibody, denosumab, a powerful antiresorptive drug, is effective against bone loss in patients with osteoporosis [3]. Although no ONJ occurrence was reported dur-

Received: 29 June 2021, Revised: 31 August 2021, Accepted: 23 September 2021

Corresponding author: Ha Young Kim

Department of Internal Medicine, Gangneung Asan Hospital, University of Ulsan College of Medicine, 38 Bangdong-gil, Gangneung 25440, Korea

Tel: +82-33-610-4580, Fax: +82-33-641-8130, E-mail: hykimmd@hanmail.net ing the early clinical study [3], the first report of ONJ in patients treated with denosumab was published in 2010 [4]. Therefore, the name "denosumab-related osteonecrosis of the jaw" (DRONJ) was proposed [5]. As it became clear that ONJ was related to the administration of antiresorptives, it was renamed "antiresorptive-related osteonecrosis of the jaw" (ARONJ) by the American Dental Association in 2011 [6]. Subsequently, in 2014, the American Association of Oral and Maxillofacial Surgeons (AAOMS) proposed the expanded designation "medication-related osteonecrosis of the jaw" (MRONJ) to include ONJ caused by anti-angiogenic agents and antiresorptives [7].

The first definition of ARONJ was published by AAOMS in 2007 and has since been updated twice. ARONJ is defined as an area of exposed bone or bone that can be probed through an intra- or extraoral fistula in the maxillofacial region, persisting for over 8 weeks in patients who are currently receiving or have

Copyright $(\odot 2021$ Korean Endocrine Society

This is an Open Access article distributed under the terms of the Creative Commons Attribution Non-Commercial License (https://creativecommons.org/ licenses/by-nc/4.0/) which permits unrestricted non-commercial use, distribution, and reproduction in any medium, provided the original work is properly cited. 
previously received treatment with antiresorptive and who have no history of radiotherapy to the jaw or obvious metastatic disease to the jaws. This definition has been adopted on a wide scale internationally and used in position papers published in Korea [8] and Japan [9].

Although it has now been over a decade since the first report of ARONJ, the mechanisms underlying this condition are not yet clear. Several factors are likely to be involved; most importantly, infection/inflammation $[10,11]$ as well as impaired bone repair [12], altered immunity [13], soft tissue toxicity [14], and angiogenesis inhibition [15] after exposure to BPs or denosumab. As local dental and periodontal infection play a major role in the occurrence of ARONJ, oral hygiene management through periodic dental check-ups has been suggested as an important approach for prevention. Moreover, there is still no effective treatment for ARONJ; thus, prevention is essential. The aim of this review was to provide up-to-date information regarding the risk factors and prevention of ARONJ from the point of view of a physician.

\section{ANTIRESORPTIVE-RELATED FACTORS}

\section{Bisphosphonate}

BPs are synthetic analogues of pyrophosphates that tightly bind to hydroxyapatite and inhibit osteoclastic bone resorption [16]. Indeed, the half-life of BPs in circulation is quite short, ranging from 30 minutes to 2 hours; however, once they have been incorporated into bone tissue, they have a long biological skeletal half-life, estimated to be up to 10 years [17].

BPs constitute the mainstay of therapy for the treatment of osteoporosis and metabolic bone disease, as well as of hypercalcemia of malignancy and bone metastases in solid tumor and multiple myeloma (MM). Currently in Korea, there are five BPs ap- proved for aforementioned indications: alendronate, risedronate, ibandronate, pamidronate, and zoledronate. In patients with osteoporosis, low-dose oral or intravenous (IV) BPs are used, but in patients with metastatic bone disease, high-dose IV BPs are mainly used (e.g., zoledronate $4 \mathrm{mg}$ IV every 4 weeks) (Table 1).

The first cases of ARONJ were reported in 2003; in patients receiving pamidronate or zoledronate, Marx [2] reported 36 cases of painful bone exposure in the mandible and/or the maxilla. Moreover, many studies have cited both the incidence and prevalence of ARONJ. However, it is difficult to estimate the exact incidence and prevalence in observational studies due to the complex diagnostic criteria of ARONJ. According to the consensus report published by the International Task Force on ARONJ [18], the incidence of ARONJ in patients with osteoporosis prescribed low-dose oral BPs or IV BPs ranges from 1.04 to 69 per 100,000 patient-years and from 0 to 90 per 100,000 patient-years, respectively. In patients with metastatic bone disease treated with high-dose IV BPs, the incidence of ARONJ ranges from 0 to 12,222 per 100,000 patient-years [18].

In Korea, Hong et al. [19] first reported that the estimated prevalence of ARONJ was $0.05 \%$ to $0.07 \%$ when oral BP used in one hospital by the retrospective review of medical charts in 2010. In addition, the Korean Association of Oral and Maxillofacial Surgeons (KAOMS) reported the preliminary results of a nationwide survey that a total of 254 cases of ARONJ occurred in 2008 based on 600,000 patients who were prescribed BPs, and the estimated frequency of ARONJ was $0.04 \%(1 / 2,300 \mathrm{BP}$ patients) [20]. In a recent study using Korean claim-data that followed 164,926 new BP users and matched-controls for 4 years, the cumulative incidence rates of ARONJ were 20.9 and 6.9 per 100,000 , respectively $(0.02 \%$ vs. $0.006 \%)$ [21]. The administration route (oral vs. IV) or BP classification was not significantly related to the risk of ARONJ. In cancer patients, Choi

Table 1. Dose and Frequency of Antiresorptive Agents Related to Antiresorptive-Related Osteonecrosis of the Jaw

\begin{tabular}{lll}
\hline Antiresorptive & \multicolumn{1}{c}{ Low dose (for osteoporosis) } & High dose (for bone metastasis) \\
\hline $\begin{array}{l}\text { Bisphosphonate } \\
\text { Alendronate }\end{array}$ & $70 \mathrm{mg}$ PO weekly or $10 \mathrm{mg}$ PO daily & \\
$\begin{array}{l}\text { Risedronate } \\
\text { Ibandronate }\end{array}$ & $5 \mathrm{mg}$ PO daily or $35 \mathrm{mg}$ PO weekly or $150 \mathrm{mg}$ PO monthly & \\
Pamidronate & $150 \mathrm{mg}$ PO daily or $3 \mathrm{mg}$ IV every 3 months & $90 \mathrm{mg} \mathrm{IV} \mathrm{every} 4$ weeks \\
Zoledronate & $30 \mathrm{mg}$ IV every 3 months & $4 \mathrm{mg} \mathrm{IV} \mathrm{every} 3-4$ weeks \\
Denosumb & $5 \mathrm{mg}$ IV yearly & $120 \mathrm{mg} \mathrm{SC}$ every 4 weeks \\
\hline PO, per oral; IV, intravenous; SC, subcutaneous. &
\end{tabular}


et al. [22] reported that the overall incidence of ARONJ was $6.9 \%$ (9/130 MM patients, 6,923 per 100,000 patient-year) in one center. However, due to the limitations of each study, the exact incidence of ARONJ is currently unknown when using $\mathrm{BP}$ in Korea.

\section{Exposure of BP}

Risk factors associated with the use of BP include drug potency, administration route (orally or IV), and duration of treatment. Because the high-dose BP used in cancer patients is IV BP, there are reports that patients with IV BP have a higher risk of developing ARONJ than those taking oral drugs. However the main factor for the development of ARONJ is the cumulative exposure to BP, considering both the dose and the frequency. There are many studies that report an increase in the risk of ARONJ as the exposure to BP increases, but it is difficult to establish a definite threshold period because the method of evaluating BP exposure is different in each study. In addition, since the effect of BPs may persist for some time after treatment has been stopped, it may be difficult to assess the risk of patients with a history of taking previous medications.

In a survey study of over 13,000 Kaiser Permanente members, the risk of ARONJ in patients with osteoporosis was doubled when oral BPs were taken for more than 4 years [23]. Oral BP exposure was determined using the health plan pharmacy databases, with prescription records available from 1994 to 2008. Barasch et al. [24] showed that the risk for ARONJ increased after 5 years of BP treatment in non-cancer patients in a case-control study based on large networks of dental practices in the USA. Duration, frequency, and dose of BP exposure were collected during the patient telephone interview. However, in an aforementioned Korean study with claim records from 2012 to 2016, defined daily dose (DDD) was used to assess the duration of treatment; it was found that the risk for ARONJ was 2.8- and 3.0-fold higher in BP users with DDD 365 to 729 and DDD $\geq$ 730 than in BP users with DDD <365 [21]. Another case-control study in Korea assessed BP exposure over 2 years prior to ARONJ using cumulative drug exposure (CDE). The risk of ARONJ was five times higher in patients with 1.5 years $<\mathrm{CDE}$ $\leq 2$ years than in those with $0<\mathrm{CDE} \leq 0.5$ years [25]. Therefore, to date, no clear threshold of duration of BP treatment that does not cause ARONJ has been identified.

\section{Denosumab}

Denosumab is a fully human monoclonal antibody that has a different mode of action from that of BP [3]. It targets and binds to the RANKL; in doing so, it prevents the activation of RANK on the surface of osteoclasts and osteoclast precursors. Inhibition of the RANKL-RANK interaction interferes with osteoclast formation, function, and survival, leading to decreased bone resorption [26]. It has a short half-life of approximately 25 to 32 days. It is used to treat osteoporosis, bone cancer (primary and metastatic), and giant cell tumor. In patients with osteoporosis, $60 \mathrm{mg}$ is administered by subcutaneous (SC) injection every 6 months; in patients with cancer, $120 \mathrm{mg}$ is administered monthly. Denosumab has a more potent antiresorptive effect than BPs and is effective even in patients who are non-responsive to BPs. In addition, unlike BP, denosumab does not permanently bind to the bone matrix; hence, the effect is reversible. The inhibitory effect on bone resorption disappears after stopping drug administration.

Shortly after denosumab was clinically introduced, ARONJ cases involving high-dose denosumab treatment for patients with cancer began to emerge in 2010 [4,27]. In Korea, the occurrence of ARONJ was reported in 2015 after the administration of high-dose denosumab to patients with breast cancer [28].

In patients with osteoporosis using low-dose denosumab, ARONJ was not reported in the first 3-year randomized controlled trial (RCT) [3]. However, in the extension study, 13 cases of ARONJ were reported after administration of low-dose denosumab for up to 10 years, resulting in an incidence of ARONJ of 50.2 per 100,000 patient-years [29]. Therefore, the duration of osteoporosis treatment is important even at low doses. In osteoporosis patients treated with denosumab, the incidence of ARONJ ranges from 0 to 30.2 per 100,000 patients per year [18].

Two phase III studies of breast and prostate cancer reported that the incidence of ARONJ was $1.1 \%$ during the 1 st year of denosumab treatment and increased to $4.1 \%$ in subsequent years [30]. A meta-analysis of six RCTs did not show a significant difference in the risk of ARONJ between the denosumab and zoledronate groups in patients with bone metastases [31]. However, other systemic analysis showed that seven of the total 35 clinical trials using denosumab reported ONJ cases, all with high doses of $120 \mathrm{mg}$ for cancer treatment. Analyses showed that the risk of ARONJ appeared to be more severe with denosumab than with zoledronate in six studies, but the incidence of ONJ was low at $0 \%$ to $2 \%$ over the 13 to 21 months of treatment [32]. Currently, the risk of ARONJ in patients with cancer under treatment with denosumab is estimated to be comparable to that in patients treated with zoledronate and is estimated to be between $0.7 \%$ and $6.9 \%$ [33]. In addition, ARONJ may develop 
rapidly in patients who switch from BP to denosumab [34], thus, caution is necessary from a prescribing physician's perspective.

\section{Other antiresorptives}

Raloxifene is a weak antiresorptive agent that is classified as a selective estrogen receptor modulator [35]. It is commonly used for the prevention and treatment of osteoporosis in postmenopausal women and was recently approved to reduce the risk of breast cancer [35]. Raloxifene can be used to treat osteoporosis in the event of ARON. However, recent reports of raloxifene-related ONJ have raised concerns about the relevance [36,37].

Romosozumab, a monoclonal antibody against the Wnt inhibitor sclerostin, demonstrates a dual effect of increasing bone formation and decreasing bone resorption [38]. This antiresorptive effect raises the concern of possible ARONJ development in patients treated with sclerostin antibodies. In a phase III osteoporosis trial, two cases of ARONJ were reported in romosozumab-treated individuals [38]. One case occurred after 12 months of romosozumab treatment related to an inadequate denture and another case occurred after 12 months of romosozumab treatment and one dose of denosumab related to a tooth extraction. A recent animal study evaluating the effects of the osteoporosis treatment dose of Scl-Ab on the development of ARONJ-like lesions in ovariectomized rats with experimental periodontitis showed that, similar to controls, no radiographic or histologic signs of ONJ-like lesions were observed [39]. This drug has not been used for long; therefore, follow-up studies are needed, but ARONJ related to romosozumab is considered rare.

\section{TRIGGERING LOCAL FACTORS}

In addition to the use of antiresorptives, many studies have tried to identify the risk factors for ARONJ, such as comorbid diseases, medications, and triggers (Table 2). However, it is not yet known which factor is most influential on the course and prognosis of ARONJ. Still, it is universally accepted that the presence of dental disease and local infection are key triggering factors for ARONJ [11,40,41]. This is related to the question of why drug-related osteonecrosis occurs specifically in the jaw and not in other bone. This may be due to the unique anatomical and microbiological characteristics of the oral cavity. The jawbone is frequently exposed to local infections and surgical procedures due to the presence of teeth, which allow the entry of colonized microbial flora in the oral cavity [42]. Another factor is that the jawbone is a region with a high rate of remodeling;

\begin{tabular}{l} 
Table 2. Risk Factors Associated with Antiresorptive-Related \\
Osteonecrosis of the Jaw \\
\hline Drug \\
Antiresorptive (bisphosphate, denousmab) \\
Antiangiogenic drug \\
Glucocorticoid \\
Dental factor \\
Dental/periodontal infection \\
Tooth extraction \\
Ill-fitting denture \\
Implant \\
Poor oral hygiene \\
Old age \\
Women \\
Smoking \\
Comorbidity \\
Cancer \\
Diabetes mellitus \\
Anemia \\
Dialysis \\
Rheumatoid arthritis \\
\hline
\end{tabular}

hence, there is a high possibility of accumulating microdamage when using BPs [43]. Moreover, ARONJ occurs twice as often in the mandible as in the maxilla, which may be attributed to the enhanced spread of infection because of decreased vascularity in the mandible [44].

Tooth extraction has been reported as the most frequent event to occur prior to ARONJ [45]. After tooth extraction, the risk of ARONJ has been estimated to be $0.5 \%$ in patients using oral BPs [46] and $1.6 \%$ to $14.8 \%$ in patients with cancer using IV BPs [7]. Therefore, most recommendations for dental care for patients taking antiresorptives have included advice against tooth extractions [7-9]. However, a growing number of reports suggest that tooth infection rather than tooth extraction is a major risk factor for ARONJ. This means that prior to tooth extraction, osteonecrosis may already be present associated with dental disease, such as periodontitis, which may have led to tooth extraction [40]. This needs to be further clarified.

Other local factors identified include dentures and implants. Among patients with cancer or IV BPs, dentures have an at least two-fold greater risk for ARONJ, likely resulting from the chronic irritation of tissue [47]. Evidence for an association between implants and ARONJ is controversial. IV BP therapy in patients with cancer is considered a clear contraindication for 
dental implants [48]. However, a systemic review including eight studies found insufficient evidence that the use of BP negatively affects implant survival [49]. A Japanese study also reported that inserting dental implants before IV BP administration was not a risk factor in patients with breast cancer [50]. In a Korean study, tooth extraction and periodontal disease were factors that increased the risk of ARONJ by 9.9- and 4.8-fold, respectively, but implants were associated with a decrease in the risk of ARONJ [21]. In addition, in a recently published study, Ryu et al. [51] analyzed the relationship between implants and ARONJ in Korean patients with osteoporosis aged 70 years and older and reported that implants were not a risk factor for ARONJ development. It is believed that this is because the implant is performed only if the tooth is extracted and there are no complications thereafter. In Korea, since 2014, as implants have been covered by national insurance for elderly patients, the number of procedures has been increasing. As this raises concerns about an increase in the occurrence of ARONJ, prophylactic dental care based on individual risk assessments should be strongly recommended.

\section{SYSTEMIC RISK FACTORS}

Most cases of ARONJ occur in association with antiresorptive use in patients with cancer, such as breast cancer, MM, prostate cancer, and renal cancer, rather than in patients with osteoporosis [45]. The risk is further increased with concomitant use of glucocorticoids, chemotherapeutic agents, antiangiogenic therapy, or radiation therapy [52]. Diabetes mellitus, rheumatoid arthritis, anemia, hyperthyroidism, dialysis, etc. have been reported as comorbidities that increase the risk $[8,9]$. Lifestyle and demographic factors, such as increased age, being female, smoking, and obesity, have been reported to be associated with an increased risk of ARONJ [53,54]. In a Korean study, there was no gender difference, and age was an independent risk factor for ARONJ development. Patients older than 80 years of age have a three-fold higher risk for ARONJ than relatively younger patients aged 50 to 59 years [21].

It is also interesting to note that no cases of ARONJ associated with long-term IV BP therapy have been reported in children [55]. However, there remains little evidence to explain the different effects of antiresorptives on bone metabolism in children.

\section{INDIVIDUAL RISK CATEGORIZATION}

For the prevention of $\mathrm{ARONJ}$, it is important to understand the individual risk level of patients receiving antiresorptive treatment through communication between the physician and the oral surgeon and to take appropriate measures accordingly. The frequency of ARONJ is intrinsically linked to the cumulative exposure to and the potency of the antiresorptives as well as the comorbidities. A recent review recommended assessing each individual's risk and implementing prophylactic therapy, taking into account the treatment regimen, duration, and risk factors [56,57]. As for the therapeutic regimen, BP and denosumab used for osteoporosis treatment are classified as low doses; monthly zoledronate $4 \mathrm{mg}$ IV and denosumab $120 \mathrm{mg}$ SC administration for patients with cancer are classified as high doses. High-dose use should be considered a high-risk factor for ARONJ occurrence, regardless of the duration of treatment or the presence of risk factors. A low risk is considered only when a low-dose treatment duration is short and there are no risk factors. Here, there is controversy regarding the cutoff of the treatment duration. According to AAOMS and other groups [7,24], 4 years is suggested as the cutoff for low-dose BP treatment; however, in recent reviews, 3 years has been proposed as a cutoff based on studies reporting an early occurrence of zoledronate- and denosumab-associated ARONJs [29,58]. Nonetheless, as mentioned earlier, it is difficult to determine a safe period in which ARONJ does not occur; thus, it is important to take into account the overall risk considering other risk factors.

\section{PROPHYLACTIC DENTAL CARE}

Primary prevention for ARONJ refers to the elimination or reduction of oral and dental risk factors by applying appropriate protocols for patients before and during antiresorptive treatment.

\section{Before antiresorptive treatment}

In the high-risk patient group, most of the current guidelines recommend a dental visit before starting antiresorptive therapy and periodic dental visits thereafter [9,34,56,57]. Preventive dental care for high-risk patients includes extracting teeth with a poor prognosis, checking dentures, and actively treating infections. It is also necessary to educate patients on oral hygiene management and ARONJ-related symptoms and to advise them to quit smoking. All invasive dental procedures should be completed at least 2 weeks to 1 month in advance as the mucosa must heal before starting the antiresorptive treatment $[9,56]$. However, in the low-risk patient group, general oral care guidelines are provided and pre-treatment dental visits are recom- 
mended only if they are unable to practice the guidelines themselves.

\section{During antiresorptive treatment}

According to the clinical practice guidelines of the American Society of Clinical Oncology (ASCO), planned invasive dental procedures, such as tooth extraction, alveoloplasty, and implants, should not be performed during antiresorptive therapy in patients with cancer. However, if an invasive dental procedure is unavoidable because the dental problem is not resolved with conservative treatment, it can be performed according to the standard protocol [59]. In addition, invasive dental treatment should be carried out with caution even in the high-risk group with a long duration of antiresorptive treatment or comorbidities. For patients at low risk of developing ARONJ, there is no need to change, or delay, planned dental treatment. To minimize the risk of ARONJ, clinicians should recommend the use of antibacterial mouthwashes and systemic antibiotics before and after the procedure.

\section{TEMPORARY DISCONTINUATION OF THE DRUG}

When a patient receiving antiresorptives must undergo dental surgery, it is controversial whether to temporarily stop the antiresorptives (Table 3) [7-9,17,33,57,60]. Drug holiday discussed in relation to ARONJ can have two meanings in practice. One is the case of stopping the drug for a certain period prophylactically before dental surgery, and the second is the case of stopping the drug after ARONJ occurs. Once ARONJ is diagnosed, antiresorptive treatment is discontinued until the treatment of ARONJ is complete; therefore, controversy exists regarding the choice for prophylactic discontinuation. If an invasive dental procedure is unavoidable in a patient who is already using antiresorptives, discontinuation of the antiresorptives before the dental procedure is not necessarily recommended in the lowrisk patient group. In high-risk patients, discontinuation of antiresorptives may be considered, owing to the risk of fracture and ARONJ, after discussion between the prescribing doctor and the dentist.

\section{Bisphosphonates}

When using BPs in patients with osteoporosis, the guidelines of the advisory board of the U.S. Food and Drug Administration, AAOMS, and others, including those of Korea and Japan, recommend BP discontinuation 2 months before dental treatment for high-risk groups considering the treatment duration and risk factors [7-9].

According to oncology guidelines, for patients with cancer receiving high-dose IV $\mathrm{BP}$, the decision to discontinue should also consider whether discontinuation of the drug may aggravate bone metastases [34]. A recent meta-analysis reported that withdrawal for high-dose antiresorptives did not reduce the risk of ARONJ in patients with cancer [61]. Considering the long half-life of BPs, stopping the drug may have no effect. In particular, for zoledronate, which is effective for up to 5 years after a single administration, the notion of stopping does not seem appropriate [62]. It may be helpful to delay dental procedures as far as possible from the last injection. According to recent Italian guidelines, it is recommended that the last administration of BPs in patients with or without cancer should be done at least 1 week before invasive dental procedures and that BP administration should be resumed at least 4 to 6 weeks after the mucous membrane has healed [46].

\section{Denosumab}

Unlike BP, denosumab has a reversible effect; therefore, discontinuation of the drug may be highly effective in reducing the risk of developing ARONJ. However, since the administration interval of denosumab is long in patients with osteoporosis, it is more reasonable to set an appropriate time for dental procedures rather than to discontinue the drug. After a single dose of denosumab, the bone resorption marker, C-terminal telopeptide of type I collagen (CTX), reaches its lowest level within 3 to 7 days and remains suppressed for at least 150 days. If the second dose is not administered after 6 months, the CTX level increases above the baseline within 3 months ( 9 months after the last injection). Hence, a delay of approximately 2 months may not increase the risk of problems that may occur because the bone turnover increases beyond normal, for example, in rebound vertebral fracture. According to these pharmacokinetic parameters, it is possible to identify an appropriate time for invasive dental procedures. This period is approximately 2 months, starting from the 5 th month after the last dose and ending at the beginning of the 7 th month [57]. A dental procedure at this time allows the next dose to be administered before the 9th month after the last injection, even if the next injection of denosumab is delayed by 4 to 6 weeks until the mucous membrane has healed. However, this approach needs validation in future studies.

For patients with cancer receiving high-dose denosumab monthly, discontinuation of the drug prior to dental procedures may be considered even though there is insufficient evidence. A 
Table 3. Comparison among Guidelines/Positions on Drug Discontinuation before Invasive Dental Procedure

\begin{tabular}{|c|c|c|c|c|}
\hline \multirow{2}{*}{ Organization } & \multirow{2}{*}{ Year } & \multirow{2}{*}{ Country } & \multicolumn{2}{|c|}{ Recommendation/Suggestion } \\
\hline & & & Patients with osteoporosis & Patients with bone metastasis \\
\hline $\begin{array}{l}\text { American Association of Oral and } \\
\text { Maxillofacial Surgeons [7] }\end{array}$ & 2014 & United States & $\begin{array}{l}\text { BP patients receiving antiresorptive therapy for } \\
\text { longer than } 4 \text { years and who have low fracture } \\
\text { risk but potentially high risk for BRONJ, } \\
\text { discontinuation of antiresorptive treatment for } \\
\text { approximately } 2 \text { months before invasive dental } \\
\text { treatment should be considered, in consultation } \\
\text { with the physician. }\end{array}$ & $\begin{array}{l}\text { Data are scant regarding the effect of } \\
\text { discontinuing intravenous } \\
\text { bisphosphonates prior to invasive } \\
\text { dental treatments should these be } \\
\text { necessary. }\end{array}$ \\
\hline $\begin{array}{l}\text { International Task Force on } \\
\text { Osteonecrosis of the Jaw [18] }\end{array}$ & 2015 & $\begin{array}{l}\text { United States, } \\
\text { Canada, } \\
\text { Europe, } \\
\text { Japan }\end{array}$ & $\begin{array}{l}\text { If the bisphosphonate treatment period is more than } \\
4 \text { years or if there are concomitant risk factors, a } \\
\text { drug holiday is recommended until the bone is } \\
\text { completely healed. }\end{array}$ & $\begin{array}{l}\text { Any necessary invasive dental } \\
\text { procedure including dental extractions } \\
\text { or implants should ideally be } \\
\text { completed prior to initiation of BP or } \\
\text { Dmab therapy. }\end{array}$ \\
\hline $\begin{array}{l}\text { Korean Society for Bone and } \\
\text { Mineral Research and the } \\
\text { Korean Association of Oral and } \\
\text { Maxillofacial Surgeons [8] }\end{array}$ & 2015 & Korea & $\begin{array}{l}\text { In patients with a duration of oral treatment longer } \\
\text { than } 4 \text { years regardless of clinical risk factors or } \\
\text { less than } 4 \text { years but with clinical risk factors, BP } \\
\text { holiday of at least } 2 \text { to } 4 \text { months should be taken } \\
\text { before dental treatment. }\end{array}$ & $\begin{array}{l}\text { Although the necessity of a drug } \\
\text { holiday is clear in cases of MRONJ, } \\
\text { there is little evidence on whether a } \\
\text { drug holiday is needed in advance for } \\
\text { prevention. }\end{array}$ \\
\hline $\begin{array}{c}\text { Japanese Allied Committee on } \\
\text { Osteonecrosis of the Jaw [9] }\end{array}$ & 2017 & Japan & $\begin{array}{l}\text { There is little clinical evidence that short-term } \\
\text { discontinuation of BPs helps to prevent the } \\
\text { occurrence of BRONJ resulting from invasive } \\
\text { dental treatments. }\end{array}$ & $\begin{array}{l}\text { Invasive dental treatments, if inevitable, } \\
\text { can be conducted without a drug } \\
\text { holiday following appropriate } \\
\text { infection control. }\end{array}$ \\
\hline $\begin{array}{l}\text { Multinational Association of } \\
\text { Supportive Care in Cancer/ } \\
\text { International Society of Oral } \\
\text { Oncology (MASCC/ISOO) and } \\
\text { American Society of Clinical } \\
\text { Oncology (ASCO) [33] }\end{array}$ & 2019 & United States & & $\begin{array}{l}\text { There is insufficient evidence to support } \\
\text { or refute the need for discontinuation } \\
\text { of the BMA before dentoalveolar } \\
\text { surgery. }\end{array}$ \\
\hline $\begin{array}{l}\text { Fundación Santa Fé (Bogotá, } \\
\text { Colombia) and the Asociación } \\
\text { Colombiana de Osteoporosis y } \\
\text { Metabolismo Mineral } \\
\text { (ACOMM) [60] }\end{array}$ & 2020 & Colombia & $\begin{array}{l}\text { It is neither necessary nor prudent to suspend } \\
\text { antiresorptives before dental surgery. } \\
\text { With denosumab, next dose administration may be } \\
\text { postponed in order to do the procedure allowing } \\
\text { adequate healing of soft tissue ( } 15 \text { days). }\end{array}$ & $\begin{array}{l}\text { It is not recommended to stop the } \\
\text { treatment with antiresorptives. }\end{array}$ \\
\hline $\begin{array}{l}\text { Italian Consensus group on ONJ } \\
\text { (IAC-ONJ) [57] }\end{array}$ & 2020 & Italy & $\begin{array}{l}\text { Suspension of BP can be considered useful } 1 \text { week } \\
\text { before surgery. } \\
\text { Suspension of denosumab is not recommended. } \\
\text { An appropriate time for invasive treatment is } \\
\text { ideally starting } 5 \text { months after the last dose and } \\
\text { beginning at } 7 \text { months. }\end{array}$ & $\begin{array}{l}\text { Suspension of BP can be considered } \\
\text { useful } 1 \text { week before surgery. } \\
\text { Last administrations of denosumab } \\
\text { (Xgeva) can be considered three } \\
\text { weeks before surgery. }\end{array}$ \\
\hline
\end{tabular}

BP, bisphosphonate; BRONJ, bisphosphonate-related osteonecrosis of the jaw; MRONJ, medication-related osteonecrosis of the jaw; BMA, bone-modifying agent.

recent experimental study reported that there was substantial healing of the areas of osteonecrosis in animals after the discontinuation of the RANKL inhibitor osteoprotegerin (OPG)-Fc but not after that of zoledronate. The authors suggest that denosumab discontinuation would provide a faster resolution of ARONJ than BP discontinuation [63]. In a phase III study comparing zoledronic acid and denosumab, drug administration was withheld from 30 days before invasive dental procedures until com- plete mucosal healing occurred [64]. Recent guideline recommend that the last administration of denosumab should be done at least 3 weeks prior to the invasive dental procedure and that administration should be resumed after the mucous membrane has healed [57]. However, there is currently no specific protocol for the discontinuation of denosumab; further studies are needed to develop an appropriate strategy. 


\section{CONCLUSIONS}

With the aging society, the use of antiresorptives for the treatment of osteoporosis will inevitably increase, and concerns about rare side effects, such as ARONJ, may increase. Because definitive treatment strategies for ARONJ have not been developed, prevention is important. This requires close collaboration between prescribing physicians and dentists. Before starting antiresorptives, the prescribing physicians should recommend dental checkups and provide guidance on oral hygiene management based on the individual patient's risk. If an invasive dental procedure is required while using the drug, it is necessary to recommend a period when the risk of ARONJ is low. In addition, it is necessary to provide the dentist with accurate information about each patient's individual risk so that the dental procedure can be performed according to the protocol. However, there are still many unclear areas, and further studies should be conducted to establish prevention and treatment protocols for ARONJ for each situation.

\section{CONFLICTS OF INTEREST}

No potential conflict of interest relevant to this article was reported.

\section{ORCID}

Ha Young Kim https://orcid.org/0000-0002-0651-2213

\section{REFERENCES}

1. Adler RA, El-Hajj Fuleihan G, Bauer DC, Camacho PM, Clarke BL, Clines GA, et al. Managing osteoporosis in patients on long-term bisphosphonate treatment: report of a task force of the American Society for Bone and Mineral Research. J Bone Miner Res 2016;31:16-35.

2. Marx RE. Pamidronate (Aredia) and zoledronate (Zometa) induced avascular necrosis of the jaws: a growing epidemic. J Oral Maxillofac Surg 2003;61:1115-7.

3. Cummings SR, San Martin J, McClung MR, Siris ES, Eastell R, Reid IR, et al. Denosumab for prevention of fractures in postmenopausal women with osteoporosis. N Engl J Med 2009;361:756-65.

4. Taylor KH, Middlefell LS, Mizen KD. Osteonecrosis of the jaws induced by anti-RANK ligand therapy. Br J Oral Maxillofac Surg 2010;48:221-3.
5. Ristow O, Gerngrob C, Schwaiger M, Hohlweg-Majert B, Kehl V, Jansen H, et al. Effect of antiresorptive drugs on bony turnover in the jaw: denosumab compared with bisphosphonates. Br J Oral Maxillofac Surg 2014;52:30813.

6. Hellstein JW, Adler RA, Edwards B, Jacobsen PL, Kalmar JR, Koka S, et al. Managing the care of patients receiving antiresorptive therapy for prevention and treatment of osteoporosis: executive summary of recommendations from the American Dental Association Council on Scientific Affairs. J Am Dent Assoc 2011;142:1243-51.

7. Ruggiero SL, Dodson TB, Fantasia J, Goodday R, Aghaloo T, Mehrotra B, et al. American Association of Oral and Maxillofacial Surgeons position paper on medication-related osteonecrosis of the jaw: 2014 update. J Oral Maxillofac Surg 2014;72:1938-56.

8. Kim KM, Rhee Y, Kwon YD, Kwon TG, Lee JK, Kim DY. Medication related osteonecrosis of the jaw: 2015 position statement of the Korean Society for Bone and Mineral Research and the Korean Association of Oral and Maxillofacial Surgeons. J Bone Metab 2015;22:151-65.

9. Japanese Allied Committee on Osteonecrosis of the Jaw, Yoneda T, Hagino H, Sugimoto T, Ohta H, Takahashi S, et al. Antiresorptive agent-related osteonecrosis of the jaw: position paper 2017 of the Japanese Allied Committee on Osteonecrosis of the Jaw. J Bone Miner Metab 2017;35:6-19.

10. Mawardi H, Giro G, Kajiya M, Ohta K, Almazrooa S, Alshwaimi $\mathrm{E}$, et al. A role of oral bacteria in bisphosphonate-induced osteonecrosis of the jaw. J Dent Res 2011;90:133945.

11. Aghaloo TL, Kang B, Sung EC, Shoff M, Ronconi M, Gotcher JE, et al. Periodontal disease and bisphosphonates induce osteonecrosis of the jaws in the rat. J Bone Miner Res 2011;26:1871-82.

12. Kim JW, Landayan ME, Lee JY, Tatad JC, Kim SJ, Kim $\mathrm{MR}$, et al. Role of microcracks in the pathogenesis of bisphosphonate-related osteonecrosis of the jaw. Clin Oral Investig 2016;20:2251-8.

13. Kalyan S, Wang J, Quabius ES, Huck J, Wiltfang J, Baines JF, et al. Systemic immunity shapes the oral microbiome and susceptibility to bisphosphonate-associated osteonecrosis of the jaw. J Transl Med 2015;13:212.

14. Reid IR, Bolland MJ, Grey AB. Is bisphosphonate-associated osteonecrosis of the jaw caused by soft tissue toxicity? Bone 2007;41:318-20.

15. Wood J, Bonjean K, Ruetz S, Bellahcene A, Devy L, Foidart 
JM, et al. Novel antiangiogenic effects of the bisphosphonate compound zoledronic acid. J Pharmacol Exp Ther 2002;302:1055-61.

16. Fleisch H. Bisphosphonates: mechanisms of action. Endocr Rev 1998;19:80-100.

17. Khan SA, Kanis JA, Vasikaran S, Kline WF, Matuszewski BK, McCloskey EV, et al. Elimination and biochemical responses to intravenous alendronate in postmenopausal osteoporosis. J Bone Miner Res 1997;12:1700-7.

18. Khan AA, Morrison A, Hanley DA, Felsenberg D, McCauley LK, O’Ryan F, et al. Diagnosis and management of osteonecrosis of the jaw: a systematic review and international consensus. J Bone Miner Res 2015;30:3-23.

19. Hong JW, Nam W, Cha IH, Chung SW, Choi HS, Kim KM, et al. Oral bisphosphonate-related osteonecrosis of the jaw: the first report in Asia. Osteoporos Int 2010;21:847-53.

20. Lee JK, Kim KW, Choi JY, Moon SY, Kim SG, Kim CH, et al. Bisphosphonates-related osteonecrosis of the jaw in Korea: a preliminary report. J Korean Assoc Oral Maxillofac Surg 2013;39:9-13.

21. Kim SH, Lee YK, Kim TY, Ha YC, Jang S, Kim HY. Incidence of and risk for osteonecrosis of the jaw in Korean osteoporosis patients treated with bisphosphonates: a nationwide cohort-study. Bone 2021;143:115650.

22. Choi WS, Lee JI, Yoon HJ, Min CK, Lee SH. Medicationrelated osteonecrosis of the jaw: a preliminary retrospective study of 130 patients with multiple myeloma. Maxillofac Plast Reconstr Surg 2017;39:1.

23. Lo JC, O’Ryan FS, Gordon NP, Yang J, Hui RL, Martin D, et al. Prevalence of osteonecrosis of the jaw in patients with oral bisphosphonate exposure. J Oral Maxillofac Surg 2010;68:243-53.

24. Barasch A, Cunha-Cruz J, Curro FA, Hujoel P, Sung AH, Vena D, et al. Risk factors for osteonecrosis of the jaws: a case-control study from the CONDOR Dental PBRN. Tex Dent J 2013;130:299-307.

25. Kwon JW, Park EJ, Jung SY, Sohn HS, Ryu H, Suh HS. A large national cohort study of the association between bisphosphonates and osteonecrosis of the jaw in patients with osteoporosis: a nested case-control study. J Dent Res 2015;94(9 Suppl):212S-9S.

26. Delmas PD. Clinical potential of RANKL inhibition for the management of postmenopausal osteoporosis and other metabolic bone diseases. J Clin Densitom 2008;11:325-38.

27. Aghaloo TL, Felsenfeld AL, Tetradis S. Osteonecrosis of the jaw in a patient on denosumab. J Oral Maxillofac Surg
2010;68:959-63.

28. You Tm, Lee KH, Lee SH, Park W. Denosumab-related osteonecrosis of the jaw: a case report and management based on pharmacokinetics. Oral Surg Oral Med Oral Pathol Oral Radiol 2015;120:548-53.

29. Bone HG, Wagman RB, Brandi ML, Brown JP, Chapurlat R, Cummings SR, et al. 10 Years of denosumab treatment in postmenopausal women with osteoporosis: results from the phase 3 randomised FREEDOM trial and open-label extension. Lancet Diabetes Endocrinol 2017;5:513-23.

30. Stopeck AT, Fizazi K, Body JJ, Brown JE, Carducci M, Diel I, et al. Safety of long-term denosumab therapy: results from the open label extension phase of two phase 3 studies in patients with metastatic breast and prostate cancer. Support Care Cancer 2016;24:447-55.

31. Chen F, Pu F. Safety of denosumab versus zoledronic acid in patients with bone metastases: a meta-analysis of randomized controlled trials. Oncol Res Treat 2016;39:453-9.

32. Boquete-Castro A, Gomez-Moreno G, Calvo-Guirado JL, Aguilar-Salvatierra A, Delgado-Ruiz RA. Denosumab and osteonecrosis of the jaw: a systematic analysis of events reported in clinical trials. Clin Oral Implants Res 2016;27: 367-75.

33. Yarom N, Shapiro CL, Peterson DE, Van Poznak CH, Bohlke K, Ruggiero SL, et al. Medication-related osteonecrosis of the jaw: MASCC/ISOO/ASCO clinical practice guideline. J Clin Oncol 2019;37:2270-90.

34. Yarom N, Lazarovici TS, Whitefield S, Weissman T, Wasserzug O, Yahalom R. Rapid onset of osteonecrosis of the jaw in patients switching from bisphosphonates to denosumab. Oral Surg Oral Med Oral Pathol Oral Radiol 2018 125:27-30.

35. Seeman E. Raloxifene. J Bone Miner Metab 2001;19:65-75.

36. Baur DA, Altay MA, Teich S, Schmitt Oswald M, Quereshy FA. Osteonecrosis of the jaw in a patient on raloxifene: a case report. Quintessence Int 2015;46:423-8.

37. Pontes HA, Souza LL, Uchoa DC, Cerqueira JM. Mandibular osteonecrosis associated with raloxifene. J Craniofac Surg 2018;29:e257-9.

38. Cosman F, Crittenden DB, Adachi JD, Binkley N, Czerwinski E, Ferrari S, et al. Romosozumab treatment in postmenopausal women with osteoporosis. N Engl J Med 2016;375: 1532-43.

39. Hadaya D, Gkouveris I, Soundia A, Bezouglaia O, Boyce RW, Stolina M, et al. Clinically relevant doses of sclerostin antibody do not induce osteonecrosis of the jaw (ONJ) in 
rats with experimental periodontitis. J Bone Miner Res 2019;34:171-81.

40. Nicolatou-Galitis O, Razis E, Galiti D, Galitis E, Labropoulos S, Tsimpidakis A, et al. Periodontal disease preceding osteonecrosis of the jaw (ONJ) in cancer patients receiving antiresorptives alone or combined with targeted therapies: report of 5 cases and literature review. Oral Surg Oral Med Oral Pathol Oral Radiol 2015;120:699-706.

41. Aghaloo TL, Cheong S, Bezouglaia O, Kostenuik P, Atti E, Dry SM, et al. RANKL inhibitors induce osteonecrosis of the jaw in mice with periapical disease. J Bone Miner Res 2014;29:843-54.

42. Katsarelis H, Shah NP, Dhariwal DK, Pazianas M. Infection and medication-related osteonecrosis of the jaw. J Dent Res 2015;94:534-9.

43. Hoefert S, Schmitz I, Tannapfel A, Eufinger H. Importance of microcracks in etiology of bisphosphonate-related osteonecrosis of the jaw: a possible pathogenetic model of symptomatic and non-symptomatic osteonecrosis of the jaw based on scanning electron microscopy findings. Clin Oral Investig 2010;14:271-84.

44. Fliefel R, Troltzsch M, Kuhnisch J, Ehrenfeld M, Otto S. Treatment strategies and outcomes of bisphosphonate-related osteonecrosis of the jaw (BRONJ) with characterization of patients: a systematic review. Int J Oral Maxillofac Surg 2015;44:568-85.

45. McGowan K, McGowan T, Ivanovski S. Risk factors for medication-related osteonecrosis of the jaws: a systematic review. Oral Dis 2018;24:527-36.

46. Dodson TB. The frequency of medication-related osteonecrosis of the jaw and its associated risk factors. Oral Maxillofac Surg Clin North Am 2015;27:509-16.

47. Vahtsevanos K, Kyrgidis A, Verrou E, Katodritou E, Triaridis S, Andreadis CG, et al. Longitudinal cohort study of risk factors in cancer patients of bisphosphonate-related osteonecrosis of the jaw. J Clin Oncol 2009;27:5356-62.

48. Jacobsen C, Metzler P, Rossle M, Obwegeser J, Zemann W, Gratz KW. Osteopathology induced by bisphosphonates and dental implants: clinical observations. Clin Oral Investig 2013;17:167-75.

49. Ata-Ali J, Ata-Ali F, Penarrocha-Oltra D, Galindo-Moreno P. What is the impact of bisphosphonate therapy upon dental implant survival?: a systematic review and meta-analysis. Clin Oral Implants Res 2016;27:e38-46.

50. Matsuo A, Hamada H, Takahashi H, Okamoto A, Kaise H, Chikazu D. Evaluation of dental implants as a risk factor for the development of bisphosphonate-related osteonecrosis of the jaw in breast cancer patients. Odontology 2016;104:36371.

51. Ryu JI, Kim HY, Kwon YD. Is implant surgery a risk factor for osteonecrosis of the jaw in older adult patients with osteoporosis?: a national cohort propensity score-matched study. Clin Oral Implants Res 2021;32:437-47.

52. Saad F, Brown JE, Van Poznak C, Ibrahim T, Stemmer SM, Stopeck AT, et al. Incidence, risk factors, and outcomes of osteonecrosis of the jaw: integrated analysis from three blinded active-controlled phase III trials in cancer patients with bone metastases. Ann Oncol 2012;23:1341-7.

53. Wessel JH, Dodson TB, Zavras AI. Zoledronate, smoking, and obesity are strong risk factors for osteonecrosis of the jaw: a case-control study. J Oral Maxillofac Surg 2008;66: 625-31.

54. Inada A, Hosohata K, Oyama S, Niinomi I, Mori Y, Yamaguchi $\mathrm{Y}$, et al. Evaluation of medication-related osteonecrosis of the jaw using the Japanese Adverse Drug Event Report database. Ther Clin Risk Manag 2018;15:59-64.

55. Nasomyont N, Hornung LN, Gordon CM, Wasserman H. Outcomes following intravenous bisphosphonate infusion in pediatric patients: a 7-year retrospective chart review. Bone 2019;121:60-7.

56. Nicolatou-Galitis O, Schiodt M, Mendes RA, Ripamonti C, Hope S, Drudge-Coates L, et al. Medication-related osteonecrosis of the jaw: definition and best practice for prevention, diagnosis, and treatment. Oral Surg Oral Med Oral Pathol Oral Radiol 2019;127:117-35.

57. Campisi G, Mauceri R, Bertoldo F, Bettini G, Biasotto M, Colella G, et al. Medication-related osteonecrosis of jaws (MRONJ) prevention and diagnosis: Italian consensus update 2020. Int J Environ Res Public Health 2020;17:5998.

58. Black DM, Delmas PD, Eastell R, Reid IR, Boonen S, Cauley JA, et al. Once-yearly zoledronic acid for treatment of postmenopausal osteoporosis. N Engl J Med 2007;356:180922.

59. Di Fede O, Panzarella V, Mauceri R, Fusco V, Bedogni A, Lo Muzio L, et al. The dental management of patients at risk of medication-related osteonecrosis of the jaw: new paradigm of primary prevention. Biomed Res Int 2018;2018: 2684924.

60. Chalem M, Medina A, Sarmiento AK, Gonzalez D, Olarte C, Pinilla E, et al. Therapeutic approach and management algorithms in medication-related osteonecrosis of the jaw (MONJ): recommendations of a multidisciplinary group of 
experts. Arch Osteoporos 2020;15:101.

61. Ottesen C, Schiodt M, Gotfredsen K. Efficacy of a highdose antiresorptive drug holiday to reduce the risk of medication-related osteonecrosis of the jaw (MRONJ): a systematic review. Heliyon 2020;6:e03795.

62. Grey A, Bolland MJ, Horne A, Wattie D, House M, Gamble $\mathrm{G}$, et al. Five years of anti-resorptive activity after a single dose of zoledronate: results from a randomized double-blind placebo-controlled trial. Bone 2012;50:1389-93.
63. de Molon RS, Shimamoto H, Bezouglaia O, Pirih FQ, Dry SM, Kostenuik P, et al. OPG-Fc but not zoledronic acid discontinuation reverses osteonecrosis of the jaws (ONJ) in mice. J Bone Miner Res 2015;30:1627-40.

64. Raje N, Terpos E, Willenbacher W, Shimizu K, Garcia-Sanz $\mathrm{R}$, Durie B, et al. Denosumab versus zoledronic acid in bone disease treatment of newly diagnosed multiple myeloma: an international, double-blind, double-dummy, randomised, controlled, phase 3 study. Lancet Oncol 2018;19:370-81. 